\title{
Analysis of vibration reduction characteristics and applicability of steel-spring floating-slab track
}

\author{
Wanming ZHAI*, Peng XU, Kai WEI \\ Traction Power State Key Laboratory, Southwest Jiaotong University, Chengdu 610031, China
}

\begin{abstract}
A coupled dynamics computation model for metro vehicles, along with a steel-spring floating-slab track, is developed based on the theory of vehicle-track coupled dynamics. Using the developed model, the influences of the thickness, length and mass of floating-slab, spring rate and its arrangement space, running speed, etc. on the time and frequency domain characteristics of steel-spring fulcrum force are analyzed. The applicability of steel-spring floatingslab track is discussed through two integrated example cases of metro and buildings possessing distinct natural vibration characteristics. It is concluded that, it is quite significant, in the optimization modular design of the parameters of steel-spring floating-slab track, to take the matching relationship of both the amplitude-frequency characteristics of steel-spring fulcrum force and natural vibration characteristics of integrated structures into comprehensive consideration. In this way the expensive steel-spring floating-slab track can be economically and efficiently utilized according to the site condition, and at the same time, the economic losses and bad social impact resulted from the resonance during usage of steel-spring floating-slab track can be avoided.
\end{abstract}

Key words: integrated structures; natural vibration characteristics; subway vibration; steel-spring floating-slab track; steel-spring fulcrum force; frequency spectrum analysis

(C) 2011 JMT. All rights reserved.

\section{Introduction}

$\mathrm{W}$ hen urban railway transit planning is conducted, it is inevitable to take certain structures into account, like hospitals, museums, theatres, and so on, which need special requirements [1-4] to meet the environmental vibration standard. Therefore, it is necessary to have measures of vibration reduction and isolation, so that these public buildings can fulfill functions. At present, the steel-spring floating-slab track is widely used to attenuate vibration effectively [5-8].

The structure of steel-spring floating-slab track is also known as mass-spring system. The ultimate principle is to install a resonator between the track and sub-rail foundation whose natural frequency is much lower than the excited frequency. That is, the concrete ballast bed slab with a certain mass and rigidity is established floatingly on the steel-spring vibration isolator that mainly

This paper was presented at the 5th International Symposium on Environmental Vibration in Chengdu, China, October 2022,2011 , and recommended by the scientific committee of the symposium to JMT

Received Nov. 9, 2011; revision accepted Nov. 29, 2011

*Corresponding author. Tel.: +86-28-87601843

E-mail: wmzhai@home.swjtu.edu.cn (W.M. ZHAI)

(C) 2011 JMT. All rights reserved

doi: 10.3969/j.issn.2095-087X.2011.04.001 includes spiral steel spring and viscous damping. The mass inertia of floating-slab is applied to balance the dynamic load produced by running trains, while the rest of unbalanced live loads and the dead loads will be delivered to the sub-rail foundation and surroundings by steel spring elements for vibration reduction.

In accordance with the vibration isolation theory of a single degree-of-freedom system, the vibration isolator will only work when the excited frequency is more than $\sqrt{2}$ times the natural frequency. Therefore, a basic principle that is generally followed in the vibration isolation design is to reduce the natural frequency of the system, which is realized in the steel-spring floating-slab design by increasing the slab thickness. On the contrary, reducing the thickness can amplify the natural frequency, which often varies within the range of 4 to $10 \mathrm{~Hz}$ and the effect of vibration isolation can be $40 \mathrm{~dB}$ at most [9].

For the moment, the combinatorial optimization research of steel-spring floating-slab track parameters mainly focuses on two aspects: firstly, building a computational model by adopting the theory of vehicle-track coupled dynamics or structural dynamics modal analysis to analyze the vibration isolation efficiency of the steelspring floating-slab track with different combinations of parameters [10-13] and secondly, direct establishment of the analytical theory or finite element model of floating- 
slab track along with sub-rail foundation, without considering the vehicle-track coupling, to study the dynamic propagation characteristics and vibration isolation efficiency of the track structure aiming at distinct parameters and excited frequencies [9,14-15]. Most scholars assume that increasing the slab thickness by ignoring the concern of the environmental conditions can extend the range of vibration isolation frequency without changing other parameters. In other words, the relationship between vibration isolation efficiency and parameters of steel-spring floating-slab track structure as well as surroundings is uncertain, and needs further research.

For that reason, from the perspective of satisfying the mutual agreement between the combinatorial optimization of steel-spring floating-slab track parameters and different external environments, a modal analysis of integrated structures in which this kind of track stays and a feature analysis of the steel-spring fulcrum force are conducted through two project case studies. Accordingly, the influential elements and the countermeasures for the fundamental frequency optimization of steel-spring floating-slab track, in the integrated structures of metro and buildings, are proposed.

\section{Coupled model of metro vehicle along with steel-spring floating-slab track}

The metro vehicle is regarded as a multi-rigid-body vibration system, and the steel-spring floating-slab track is simplified into a double-layer elastic beam model. The coupled dynamics computational model of metro vehicle along with steel-spring floating-slab track is created based on the theory of vehicle-track coupled dynamics, and used to analyze the fulcrum force spectrum of steel spring.

The metro vehicle model, as shown in Fig. 1, is composed of seven rigid bodies: car body, fore and rear frameworks, and four wheel sets. Ten degrees of freedom in total are taken into account, including the vertical motion and nutation of the car body and frameworks, as well as the vertical motion of wheel sets.

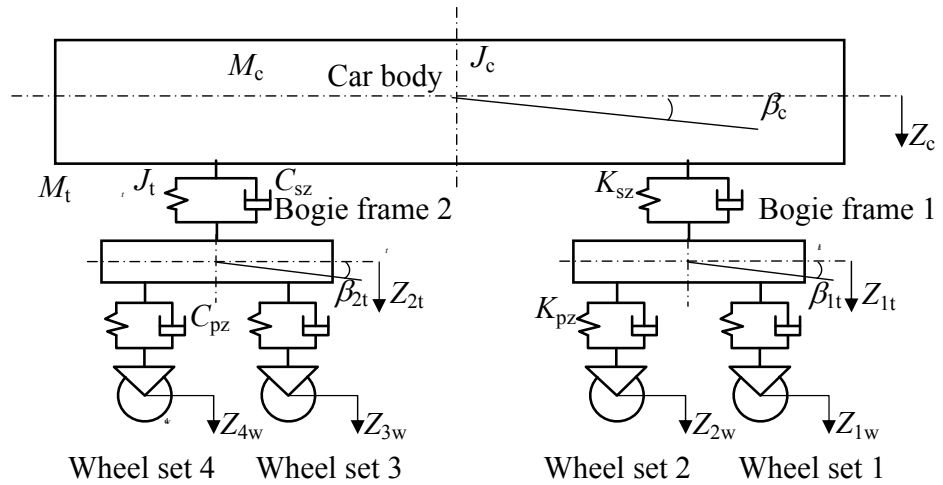

Fig. 1 Dynamic model of metro vehicle

The steel-spring floating-slab track, whose cross section and vertical dynamic model are shown in Figs. 2 and 3 , respectively, is comprised of four parts: reinforced concrete floating slab, elastic supports, concrete base, and fasteners.

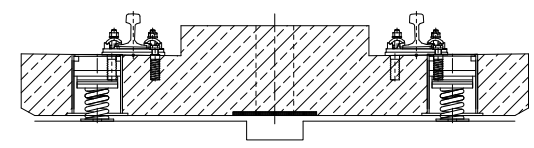

Fig. 2 Steel-spring floating-slab track

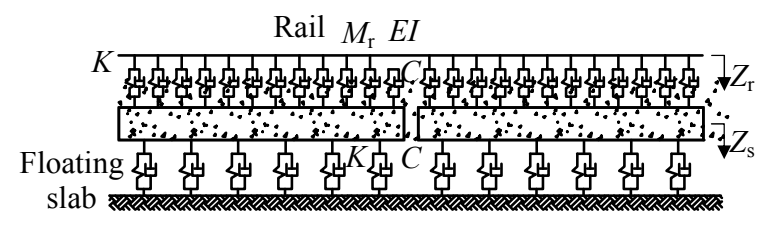

Fig. 3 Dynamic model of steel-spring floating-slab track

\section{Amplitude-frequency characteristics of steel-spring fulcrum force}

The steel-spring fulcrum force, a direct acting force, is delivered from track to the foundation in the train operation, which is considered to be the exciting force resulting in structural vibration in the integrated structures. Consequently, it is quite necessary to analyze the time and frequency domain characteristics of steel-spring fulcrum force in detail with diverse parameters, and the dynamic characteristics law should be acquired.

Thirteen different calculation schemes, as listed in Table 1, are set up to study the impact of structural parameters of floating slab on the characteristics of steelspring fulcrum force. Among them, scheme 1 is the basic one. Slab thickness is changed in schemes 2, 3, and 4 with other parameters remaining invariant, while slab length and arrangement of spring are altered in schemes 
Table 1 Calculation schemes of fulcrum force spectrum of steel spring

\begin{tabular}{|c|c|c|c|c|c|c|c|c|c|c|}
\hline $\begin{array}{c}\text { Condition } \\
\text { No. }\end{array}$ & $\begin{array}{c}\text { Mass } \\
(\mathrm{kg})\end{array}$ & $\begin{array}{l}\text { Width } \\
\text { (m) }\end{array}$ & $\begin{array}{c}\text { Thickness } \\
(\mathrm{cm})\end{array}$ & $\begin{array}{l}\text { The number } \\
\text { of springs } \\
\text { on one side }\end{array}$ & $\begin{array}{l}\text { Length } \\
\text { (m) }\end{array}$ & $\begin{array}{l}\text { Rigidity of } \\
\text { the spring } \\
\left(\mathrm{MN} \cdot \mathrm{m}^{-1}\right)\end{array}$ & $\begin{array}{c}\text { Speed } \\
\left(\mathrm{km} \cdot \mathrm{h}^{-1}\right)\end{array}$ & $\begin{array}{c}\text { Frequency } \\
(\mathrm{Hz})\end{array}$ & State & $\begin{array}{c}\text { Track } \\
\text { irregularity } \\
\text { type }\end{array}$ \\
\hline 1 & 96134.5 & 4.4 & 70 & 21 & 25 & 6.6 & 30 & 5.99 & Basic scheme & \multirow{13}{*}{$\begin{array}{l}\text { Grade } 5 \\
\text { spectrum } \\
\text { in U.S.A }\end{array}$} \\
\hline 2 & 82401 & 4.4 & 60 & 21 & 25 & 6.6 & 30 & 6.46 & & \\
\hline 3 & 109868 & 4.4 & 80 & 21 & 25 & 6.6 & 30 & 5.60 & Different thickness & \\
\hline 4 & 68667.5 & 4.4 & 50 & 21 & 25 & 6.6 & 30 & 7.06 & & \\
\hline 5 & 49990 & 4.4 & 70 & 11 & 12.5 & 6.6 & 30 & 5.96 & $\begin{array}{l}\text { Different slab length } \\
\text { /arrangement }\end{array}$ & \\
\hline 6 & 115361.4 & 4.4 & 70 & 21 & 30 & 6.6 & 30 & 5.51 & of the steel spring & \\
\hline 7 & 96134.5 & 4.4 & 70 & 21 & 25 & 5.3 & 30 & 5.37 & Different rigidity & \\
\hline 8 & 53500 & 4.4 & 70 & 21 & 25 & 6.6 & 30 & 8.01 & \multirow{3}{*}{ Different mass } & \\
\hline 9 & 34240 & 4.4 & 70 & 21 & 25 & 6.6 & 30 & 10.13 & & \\
\hline 10 & 23778 & 4.4 & 70 & 21 & 25 & 6.6 & 30 & 12.15 & & \\
\hline 11 & 96134.5 & 4.4 & 70 & 21 & 25 & 6.6 & 15 & 5.99 & \multirow{3}{*}{ Different speed } & \\
\hline 12 & 96134.5 & 4.4 & 70 & 21 & 25 & 6.6 & 45 & 5.99 & & \\
\hline 13 & 96134.5 & 4.4 & 70 & 21 & 25 & 6.6 & 60 & 5.99 & & \\
\hline
\end{tabular}

5 and 6. Spring rate is converted in scheme 7, and the influence of floating-slab mass is studied in schemes 8, 9, and 10. Running speed is varied in schemes 11, 12, and 13 .

\subsection{Effect of floating-slab thickness on fulcrum force characteristics}

Fig. 4 shows the time-history curve of single steelspring fulcrum force in calculation scheme 1 .

The time segments that every vehicle passes through can be clearly recognized from the curve in Fig. 4, while the contrary is the case for every bogie. The maximum value of steel-spring fulcrum force, which is 28.90, $29.28,29.42$, and $30.51 \mathrm{kN}$ successively in calculation schemes 1 to 4 , tends to increase a little, with increasing floating-slab thickness and decreasing first natural frequency simultaneously (see Table 1). The variation trend is shown in Fig. 5.

The amplitude-frequency characteristic curves of steel-spring fulcrum force, with different floating-slab thicknesses in calculation schemes 1 to 4 , are illustrated in Fig. 6. It can be seen that, the frequency component of the steel-spring fulcrum force mainly contains four portions: $f_{0}, f_{1}, f_{2}$, and $f_{3}$, all of which are marked in the figure where $f_{0}=0.34 \mathrm{~Hz}, f_{1}=0.68 \mathrm{~Hz}$, and $f_{2}=1.02 \mathrm{~Hz}$, keeping the same for diverse thicknesses; and $f_{0}=V / L_{a}$, where $V$ is the running speed, and $L_{a}$ is the length of vehicle (similarly hereinafter). Moreover, $f_{1}=2 f_{0}$, and $f_{2}=3 f_{0}$; and $f_{3}$, however, distinctly varies under the circum stances of different thicknesses. $f_{3}$ is reduced to $7.3,6.3$,

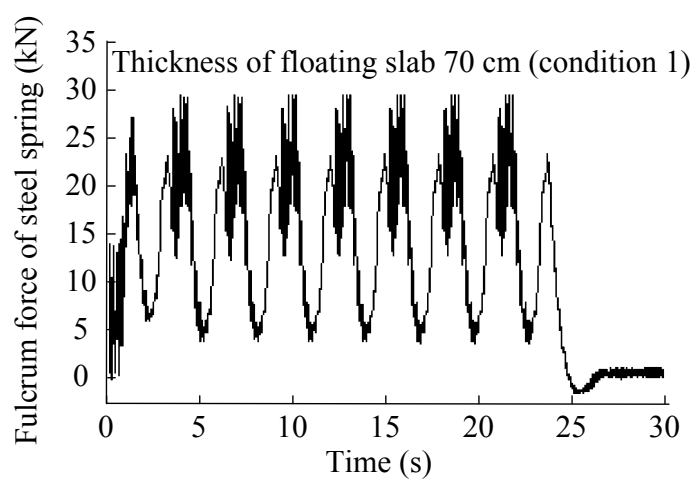

Fig. 4 Time-history curve of single steel-spring fulcrum force in calculation scheme 1

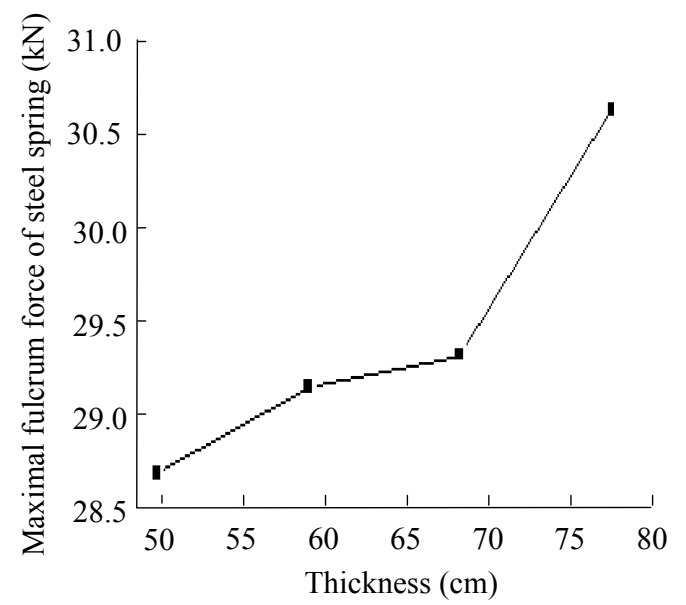

Fig. 5 Relationship between steel-spring fulcrum force and slab thickness 


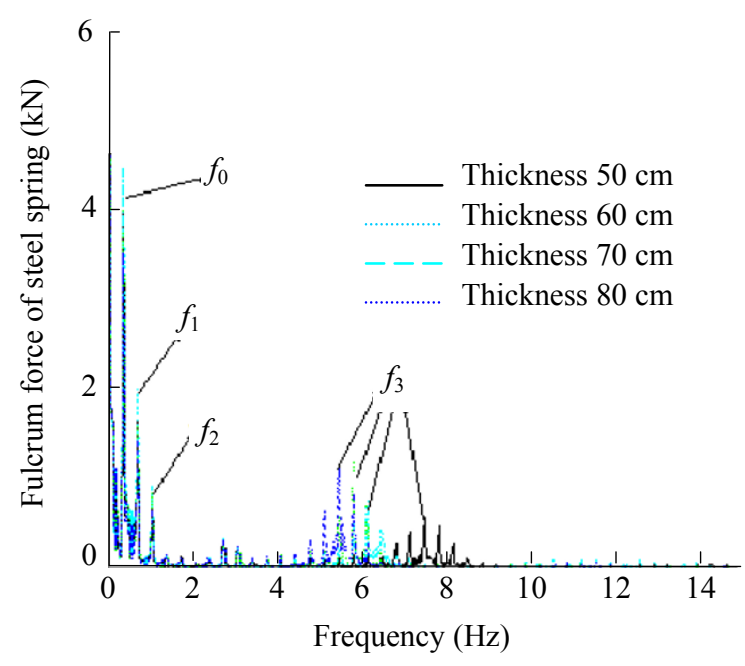

Fig. 6 Amplitude-frequency characteristic curves of steelspring fulcrum force with different slab thickness

and $5.5 \mathrm{~Hz}$ as the thickness increases. They come close to the first natural frequency of the floating slab, but the corresponding amplitudes indicate an obviously increasing tendency. The same rule can be observed for the frequency component and its relationship with vehicle and track in all calculation schemes.

\subsection{Effect of floating-slab length on fulcrum force characteristics}

Both the slab length and spring number are halved in scheme 5, which makes the spring arrangement identical as in scheme 1. Compared to scheme 1, the slab length in scheme 6 is increased to $30 \mathrm{~m}$ while the spring number remains unchanged. The amplitude-frequency characteristic curves of steel-spring fulcrum force with different floating-slab lengths are illustrated in Fig. 7. The similar conclusions to those in Section 3.1 can be drawn: there are four parts of frequency $f_{0}, f_{1}, f_{2}$, and $f_{3} ; f_{3}$ is equal to $5.9 \mathrm{~Hz}$, keeping the same with the slab length changing from 12.5 to $25 \mathrm{~m}$; and, $f_{3}$ tends to be $5.5 \mathrm{~Hz}$ in the proximity of the first natural frequency of floating slab. The slab length is $30 \mathrm{~m}$ in scheme 6 , but the corresponding amplitudes are little changed.

\subsection{Effect of steel-spring rate on fulcrum force charac- teristics}

Fig. 8 shows a similarity in the amplitude-frequency characteristics of steel-spring fulcrum force of two distinct spring rates as described in Section 4.1. The difference is that $f_{3}$ is accordingly minimized to $5.2 \mathrm{~Hz}$ when the spring rate is reduced to $5.3 \mathrm{MN} / \mathrm{m}$, and similarly, appears around the first natural frequency when the corresponding amplitudes vary little.

\subsection{Effect of floating-slab mass on fulcrum force char- acteristics}

As the mass decreases in Fig. 9, $f_{3}$ is gradually increased to $5.9,7.9,10$, and $12 \mathrm{~Hz}$ in the vicinity of the first natural frequency, which presents a similar influence law to floating-slab thickness. This means that simply reducing the slab mass makes $f_{3}$ increase while the corresponding amplitudes are clearly minimized.

\subsection{Effect of running speed on fulcrum force characteristics}

Fig. 10 indicates that when the running speed increses from 15 to $60 \mathrm{~km} / \mathrm{h}$, the corresponding maximum fulcrum force of the steel spring increases approximately linearly form 28.2 to $32.2 \mathrm{kN}$.

The amplitude-frequency characteristic curves of steel-spring fulcrum force with different running speeds are illustrated in Fig. 11, which shows that $f_{0}, f_{1}$ and $f_{2}$ change distinctly with the running speed. For example, when the speed is $15 \mathrm{~km} / \mathrm{h}, f_{0}=0.17 \mathrm{~Hz}, f_{1}=0.34 \mathrm{~Hz}$, and

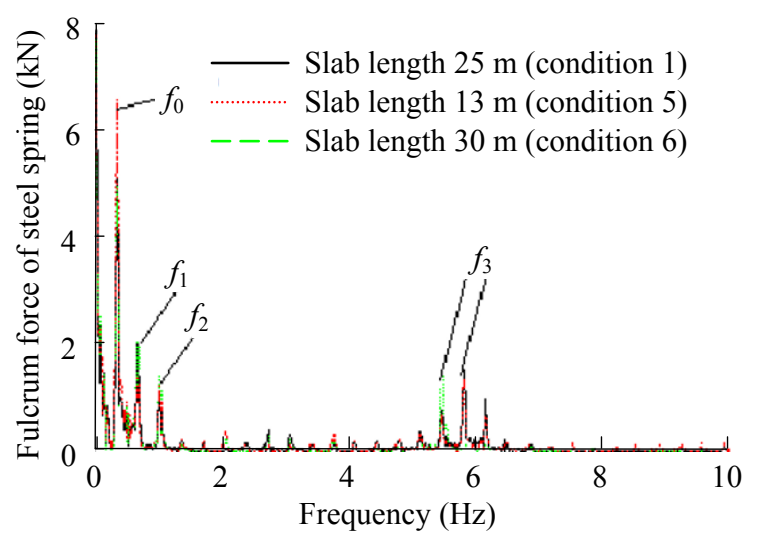

Fig. 7 Amplitude-frequency characteristic curves of steelspring fulcrum force with different slab length

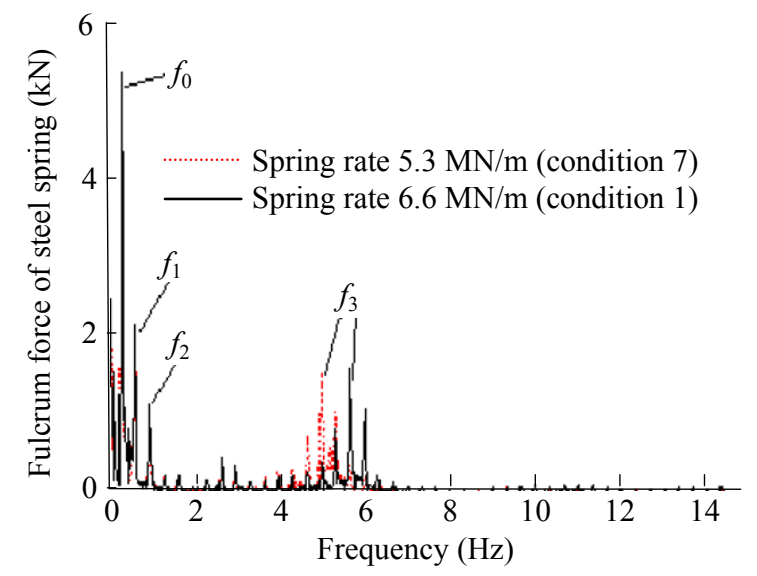

Fig. 8 Amplitude-frequency characteristic curves of fulcrum force with different spring rate 
$f_{2}=0.51 \mathrm{~Hz}$; for $30 \mathrm{~km} / \mathrm{h}, f_{0}=0.34 \mathrm{~Hz}, f_{1}=0.68 \mathrm{~Hz}$, and $f_{2}=1.02 \mathrm{~Hz}$, for $45 \mathrm{~km} / \mathrm{h}, f_{0}=0.51 \mathrm{~Hz}, f_{1}=1.02 \mathrm{~Hz}$, and $f_{2}=1.53 \mathrm{~Hz}$, and for $60 \mathrm{~km} / \mathrm{h}, f_{0}=0.68 \mathrm{~Hz}, f_{1}=1.36 \mathrm{~Hz}$, and $f_{2}=2.04 \mathrm{~Hz}$. However, all of these can meet the basic law of $f_{0}=V / L_{a}, f_{1}=2 f_{0}$, and $f_{2}=3 f_{0}$. In addition, $f_{3}$ is approximately equal to $5.90 \mathrm{~Hz}$, close to the first natural frequency with significantly changed corresponding amplitudes.

\section{Applicability of steel-spring floating-slab track}

\subsection{Engineering background}

\subsubsection{Integrated project I}

(1) In integrated structures that adopt a pile foundation as base, a double-deck subway station including platform and hall is located below the ground with seven-layer concrete frame structure above ground. The structural style is simple, and there is no obvious architectural

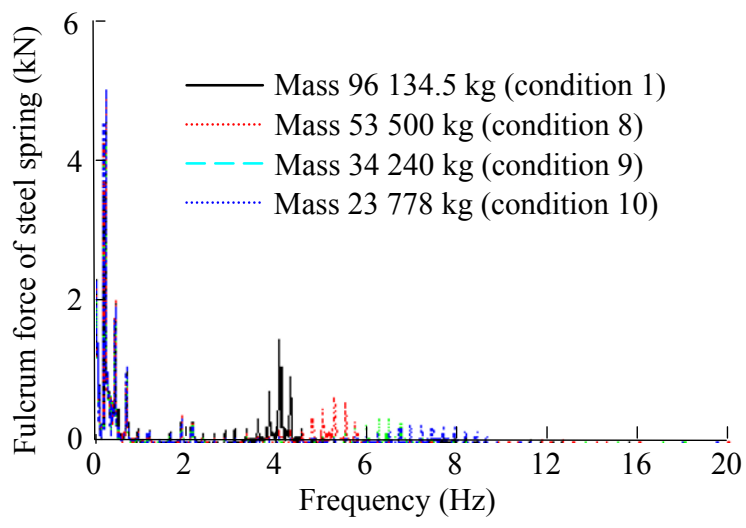

Fig. 9 Amplitude-frequency characteristic curves of fulcrum force with different slab masses

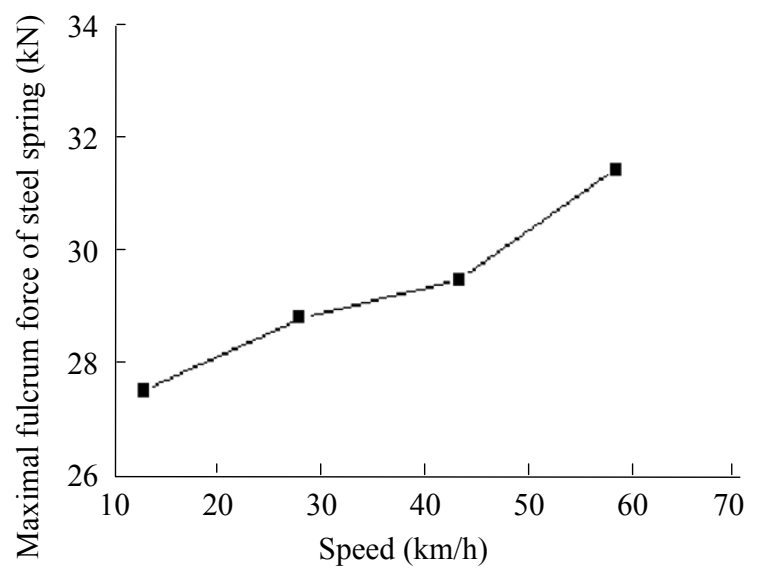

Fig. 10 Variation of Maximum fulcrum force with running speed differences on each cross section (the cross-sectional schematic is shown in Fig. 12).

(2) Cologne egg, which is a high-elasticity vibrationreduction fastener (referred to as high-elasticity fastener), is applied in the subway station.

(3) From the site operational conditions, train crossing does not exist in the station, and the average speed for pulling in and out is within $30 \mathrm{~km} / \mathrm{h}$.

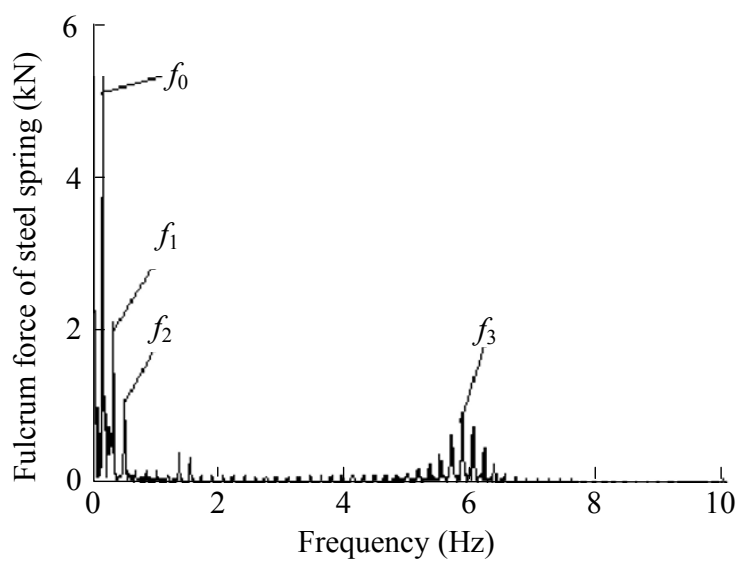

(a) Speed $15 \mathrm{~km} / \mathrm{h}$ (condition 11)

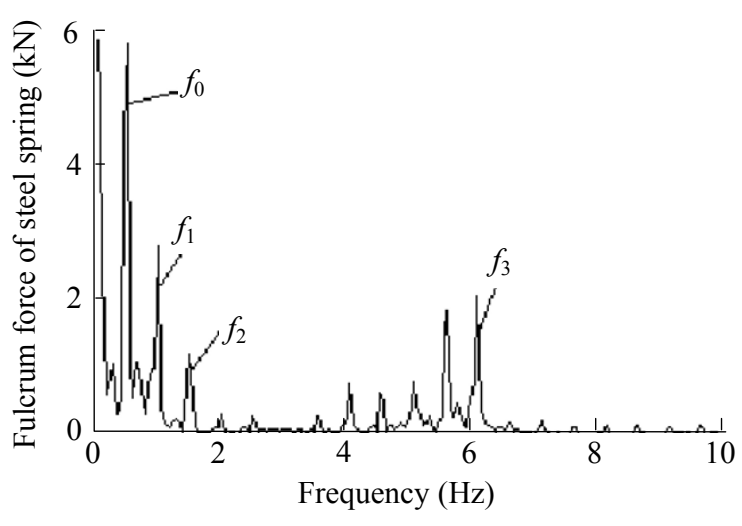

(b) Speed $45 \mathrm{~km} / \mathrm{h}$ (condition 12)

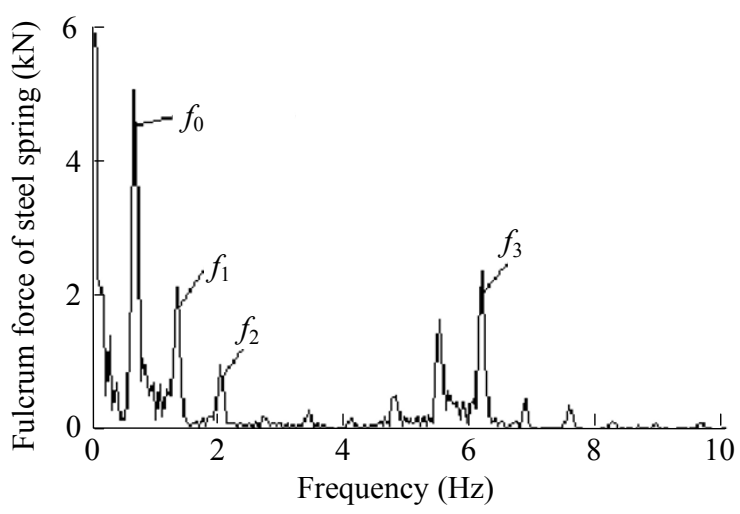

(c) Speed $60 \mathrm{~km} / \mathrm{h}$ (condition 13)

Fig. 11 Amplitude-frequency characteristic curves of fulcrum force with different running speeds 


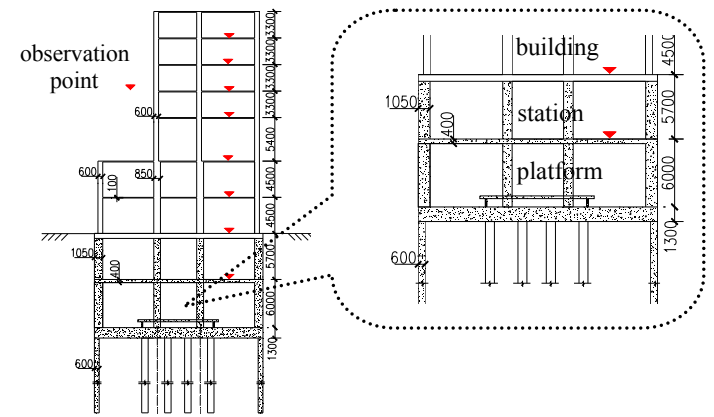

Fig. 12 Cross-sectional schematic of the integrated project I

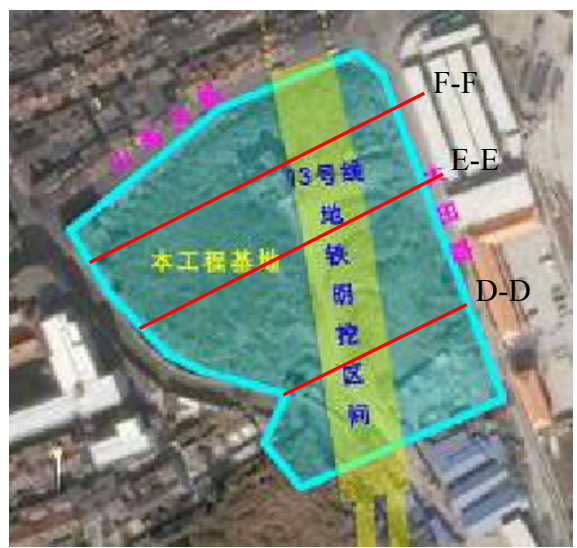

(a) Plane schematic

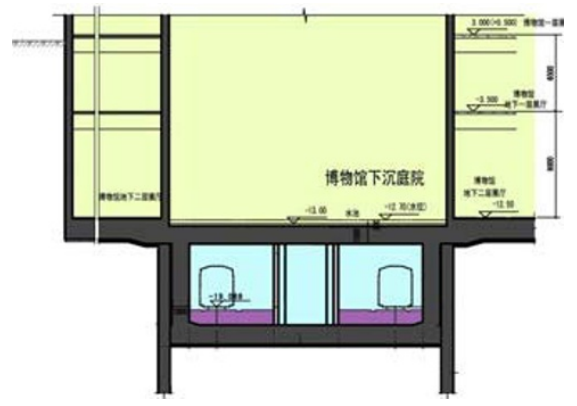

(b) Cross-sectional schematic

Fig. 13 Schematic diagram of the integrated structures of metro and public buildings

\subsubsection{Integrated project II}

(1) In the structural design of the integrated project of public buildings and metro, there are three main characteristics: after traversing $180 \mathrm{~m}$ under the buildings, the metro extends about $30 \mathrm{~m}$ more to the north and reaches the platform area of the subway station close to the buildings. Rigid connection is designed between the top plate of metro structure and the base board of buildings in the traversing section for structural stress coordination, etc. Given the elements like function cost, aesthetics, and environmental harmony, and so forth, the inside structures of these public buildings are complexly designed; for instance, the slab spans between floors vary considerably, including 5, 6, 8, 12, 13, and $16 \mathrm{~m}$ (the schematic diagram of the structural type is illustrated in Fig. 13).

(2) The major structure of public buildings is composed of two layers underground and three layers overground. The excavation area of foundation pit is $15022 \mathrm{~m}^{2}$ with a depth of $17.3 \mathrm{~m}$. The excavation depth of tunnel interval in the pit is $25.3 \mathrm{~m}$, and the pile foundation is arranged beneath the base board of both the metro and public buildings.

(3) Steel-spring floating-slab vibration-reduction track is suggested to be used in this metro interval, but no similar experience and related theory yet can provide references for determining the parameters reasonably.

(4) Since the project has not been completed yet, the metro operational conditions can be considered in the long term. That is, the metro vehicle with 8 cars in group runs on irregular track at a speed of $30 \mathrm{~km} / \mathrm{h}$ under the public buildings.

\subsection{Modal analysis of integrated structures}

\subsubsection{Integrated project I}

A 2D finite-element modal-analysis model is created according to the cross section of integrated project I. In the model, the base board where the pile foundation is arranged and the bottom of diaphragm wall are completely constrained, while other positions are free (similarly hereinafter).

When the accumulative ratio of the integrated structures of metro and building reaches $80.2 \%$ (the accumulative vibration mass is 400.29 ton, the mass ratio of vertical free vibration with different natural frequencies is obtained by subspace iteration modal calculation, as shown in Fig. 14. It can be seen that, the vertical vibration mass of the integrated structures is mainly focused on the range of 17 to $30 \mathrm{~Hz}$, and the ratio of vibration mass to total mass is $66.93 \%$. However, within 4 to $10 \mathrm{~Hz}$, i.e., the common natural frequency of floating slab, the vertical vibration mass is extremely small and negligible. Results from calculation show that the relatively large mass ratio of vibration is $0.00155 \%$ at the frequency of $8.97 \mathrm{~Hz}$, which is much less than $0.706 \%$ at $11.08 \mathrm{~Hz}$.

\subsubsection{Integrated project II}

Compared with integrated project I, the inside structure of integrated project II is more complicated. Three typical sections (three cutting positions of public building, illustrated in Fig. 13) are selected to conduct the $2 \mathrm{D}$ modal analysis. The result of the D-D section is 
merely presented, as Fig. 15 shows, since the conclusions of each section are similar.

When the vertical vibration mass with every order of natural frequency of vibration in the D-D section of the public building reaches 1242 ton in all (occupying $82.2 \%$ of the total mass), the mass ratio chart of vertical free vibration with different natural frequencies, as shown in Fig. 15, indicates that the sensitive frequency of the D-D section is mainly concentrated upon the medium and high frequency range of 20 to $80 \mathrm{~Hz}$ (the same with the other two sections). The ratio of vertical vibration mass to total mass can be $55.53 \%$. Besides that within 4 to $10 \mathrm{~Hz}$ natural frequency of floating slab, the vertical vibration mass of the $\mathrm{D}$-D section is relatively large near the frequency of $6.45 \mathrm{~Hz}$. Moreover, the vibration of this section is found to be comparatively large and intensive on the $12 \mathrm{~m}$-span floor plate through its mode of vibration (as shown in Fig. 16).

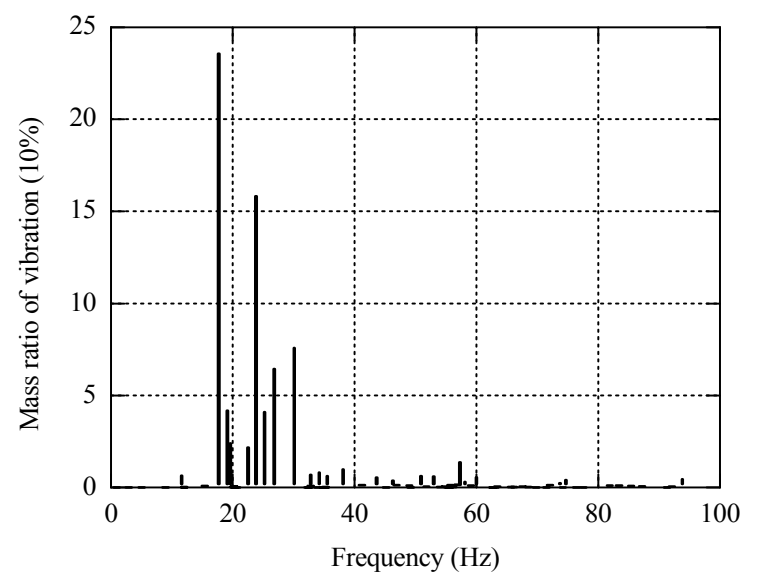

(a) $0-95 \mathrm{~Hz}$

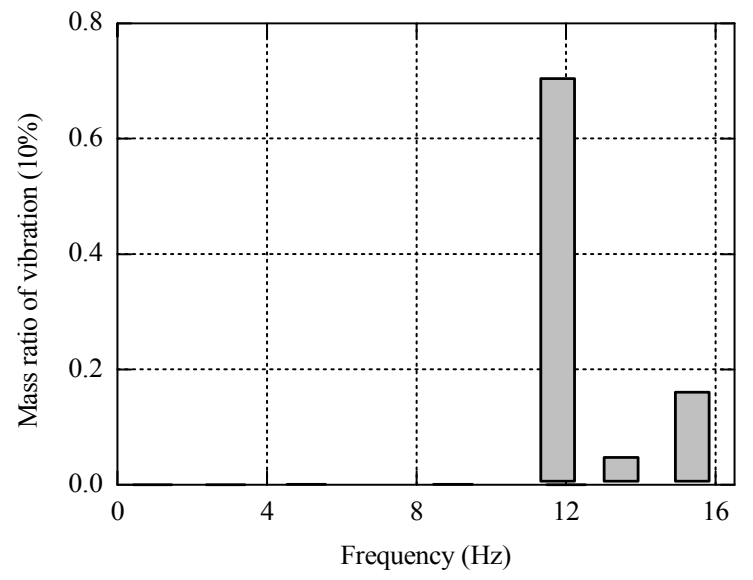

(b) $0-10 \mathrm{~Hz}$

Fig. 14 Mass ratio of free vertical vibration of different natural frequencies of 2D structure model of the project I

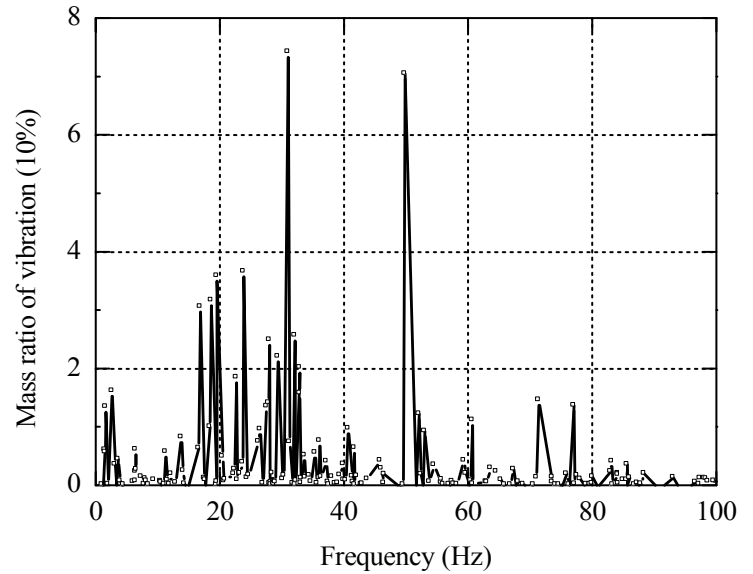

(a) D-D section $0-100 \mathrm{~Hz}$

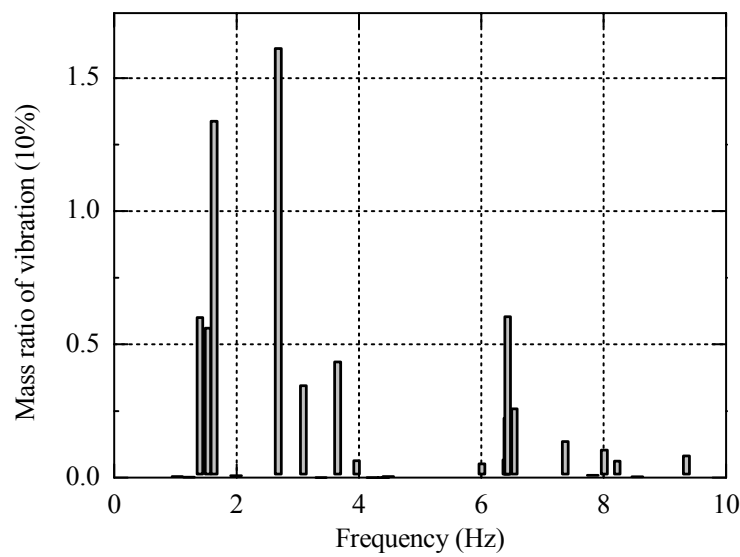

(b) D-D section $0-10 \mathrm{~Hz}$

Fig. 15 Mass ratio of vertical free vibration of different natural frequencies in the 2D structure model of the project II

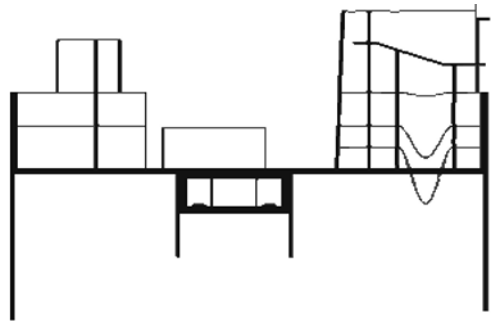

Fig. 16 Vibration mode with $6.45 \mathrm{~Hz}$ of D-D section

From the above 2D modal-analysis results, it can be concluded that the floating slab with relatively low natural frequency (close to $4 \mathrm{~Hz}$ ) can be selected to prevent resonance in the traditional viewpoint. In addition, the floating slab with high natural frequency (near $10 \mathrm{~Hz}$ ) can be chosen as well, making it as far as possible to avoid the sensitive frequency of $6.4 \mathrm{~Hz}$ or $5.6 \mathrm{~Hz}$, for which the mass ratio of vertical vibration is comparatively large and concentrated in the range of 4 to $10 \mathrm{~Hz}$. 


\section{Conclusions}

(1) Frequency components of the steel-spring fulcrum force is mainly related to the length and running speed of rolling stocks, and the natural frequency of floating slab. The components can be divided into two types: one depends on structural characteristics of rolling stock, having a frequency value equal to the ratio of speed to length, or an integer multiple of the ratio; and the other depends on inherent characteristics of floating slab, having a frequency in the vicinity of its natural frequency.

(2) Within the floating-slab parameters in this study, the amplitude of frequency component (over $20 \mathrm{~Hz}$ ) of steel-spring fulcrum force is very small and the maximum fulcrum force tends to decrease with the reduction of slab thickness, which is also true for merely lowering the slab mass.

(3) Modal analysis indicates that the vertical vibration mass of integrated structures of metro and buildings will be high in the frequency range of 20 to $80 \mathrm{~Hz}$, with the accumulative mass ratio of vibration exceeding $50 \%$. In addition, the sensitive frequency band within $10 \mathrm{~Hz}$ is close to $8.97 \mathrm{~Hz}$, and the bandwidth is narrow in project I with accumulative vibration mass being extremely low. On the contrary, in the integrated structures of project II, the frequency band, which is mainly focused on below $8 \mathrm{~Hz}$, is wider, and the accumulative vibration mass is higher. The diverse mass distribution of vertical vibration in different structures within 4 to $10 \mathrm{~Hz}$ is caused mainly by the distinct combinations of elements, such as structural size (span, thickness, etc.) of floor plate (or column), rigidity, and so on.

(4) The larger the reaction force amplitude near the natural frequency of steel-spring floating-slab, the greater the forced vibration response at the corresponding frequency will be. However, if the vibration mass of the integrated structures near the frequency domain of steelspring floating-slab is very low, the comprehensive effect encountering in the same frequency is undetermined. Consequently, it involves an issue of agreement of the reaction force amplitude near the natural frequency of steel-spring floating-slab along with the vibration characteristics of integrated structures in the corresponding frequency.

\section{Acknowledgements}

This research was supported by the Key Project of Science and Technology in an Action of Shanghai Scientific and Technological Innovation (No. 09231201600), the National Natural Science Foundation of China (No. 50823004), and the Science and Technology Department of Sichuan Province.

\section{References}

[1] K.F. Li, W.N. Liu, X.J SUN, et al., In-situ test and analysis on the vibration mitigation measures of the elevated line in Beijing metro line 5, China Railway Science, 2009, 30(4): 25-29 (in Chinese).

[2] H. Saurenman, J. Phillips, In-service tests of the effectiveness of vibration control measures on the BART rail transit system, Journal of Sound and Vibration, 2006, 293(3-5): 888-900.

[3] F. Kirzhner, G. Rosenhouse, Y. Zimmels, Attenuation of noise and vibration caused by underground train, using soil replacement, Tunneling and Underground Space Technology, 2006, 21(5): 561-567.

[4] R.D. Li, Metro-induced ground vibration and their impacts on precision instrument, Chinese Journal of Rock Mechanics and Engineer, 2008, 27(1): 206-214 (in Chinese).

[5] F. Cui, C.H. Chew, The effectiveness of floating slab track system part I- receptance methods, Applied Acoustics, 2000, 61(4): 441-453.

[6] G. Lombaert, G. Degrande, B. Vanhauwere, et al., The control of ground-borne vibrations from railway traffic by means of continuous floating slabs, Journal of Sound and Vibration, 2006, 297(3-5): 946-961.

[7] R.A. Carman, P. Eter Smoluchowski, L. Arvey, et al., Floating slab track bed design to control ground borne noise from Newmark-Elizabeth rail light rail transit, In: Proceedings of 9th National Light Rail Transit Conference, Portland Oregon, Nov. 16-18, 2003.

[8] S.J. Cox, A. Wang, C. Morison, et al., A test rig to investigate slab track structures for controlling ground vibration, Journal of Sound and Vibration 2006, 293(3-5): 901-909.

[9] D.Y. Ding, W.N. Liu, B.C. Zhang, et al., 3-D numerical study on vibration isolation performance of special floating slab track in lab, Journal of the China Railway Society, 2009, 31(6): 58-62 (in Chinese).

[10] C.B. Cai, Z.J. Liu, R.K. Zhao, Dynamical design of floating slab in track transition section, Railway Engineering, 2003, 12: 41-44 (in Chinese).

[11] X. Jun, Y. Wang, D. He, et al., Model of vertical vibration of train and floating slab track system in urban rail transit system, Journal of Central South University: Science and Technology, 2008, 39(3): 596-601 (in Chinese).

[12] D.Y. Ding, W.N. Liu, B.C. Zhang, et al., Modal analysis on the floating slab track, Journal of the China Railway Society, 2008, 30(3): 61-64 (in Chinese).

[13] C.Z. Geng, M.L. Lou, Vibration model analysis of floating slab track system, Journal of Tongji University (Natural Science), 2006, 34(9): 1201-1205 (in Chinese).

[14] A.J. Gu, H.L. Zhang, Analyses of vibration isolation effect in different frequency band for steel-spring floating slab track, Noise and Vibration Control, 2009, 29(1): 3942 (in Chinese).

[15] Z.G. Li, T.X. Wu, Study on the vibration isolation performance of floating slab track using dynamic receptance method, Journal of Vibration Engineering, 2009, 20(3): 39-42 (in Chinese). 